\title{
Écrire ailleurs sur les prisons communistes
}

Paul Goma La passion selon Pitești

\section{Adriana Decu}

Traducteur : Claudia Drăgănoiu (traduction du roumain)

\section{OpenEdition \\ Journals}

Édition électronique

URL : https://journals.openedition.org/cher/10118

DOI : $10.4000 /$ cher. 10118

ISSN : 2803-5992

\section{Éditeur}

Presses universitaires de Strasbourg

\section{Édition imprimée}

Date de publication : 1 décembre 2013

Pagination : 59-66

ISBN : 978-2-86820-560-5

ISSN : 1968-035X

Référence électronique

Adriana Decu, «Écrire ailleurs sur les prisons communistes », reCHERches [En ligne], 11 | 2013, mis en ligne le 08 février 2022, consulté le 09 février 2022. URL : http://journals.openedition.org/cher/10118 ; DOI : https://doi.org/10.4000/cher.10118

\section{c) (7)(2)}

Ce(tte) œuvre est mise à disposition selon les termes de la Licence Creative Commons Attribution Pas d'Utilisation Commerciale - Partage dans les Mêmes Conditions 4.0 International. 


\title{
Écrire ailleurs sur les prisons communistes \\ Paul Goma La passion selon Pitești ${ }^{1}$
}

\author{
AdRIANA DECU \\ Université de Bucarest
}

\begin{abstract}
$\mathrm{O}$ n remarque souvent qu'une fois rescapés d'un régime totalitaire, qu'il s'agisse du fascisme ou du communisme, des intellectuels qui n'avaient jamais écrit auparavant se sentent obligés de partager leur expérience souvent traumatisante avec leur société d'adoption. Cette nécessité psychologique est explicable - c'est le devoir de l'exilé envers les moins chanceux que lui demeurés au pays natal et dont la voix ne peut se faire entendre qu'a travers ses propres écrits.

De ce point de vue donc, la littérature carcérale présente un double défi. Premièrement, comme tout autre récit autobiographique, elle se nourrit de la réalité mais de manière partielle car il s'agit en réalité d'une autofiction. En effet, la littérature carcérale fait vaciller les notions mêmes de réalité, de vérité, de sincérité, de fiction, en usant de manière inattendue du champ de la mémoire. En second lieu, surtout lorsqu'il met en question des réalités perdurant sous les régimes totalitaires, ce type de littérature se propose aussi de "rendre justice» à ceux qui continuent de subir les mêmes traitements dans leurs pays d'origine, comme mentionné plus haut. En résumé, toute littérature carcérale comprend à la fois une dimension auto-fictionnelle (notons que l'autofiction n'est pas l'antonyme de la réalité, mais qu'elle en est plutôt son interprétation subjective) et une dimension éthique: il s'agit d'un type particulier d'art engagé.
\end{abstract}

1 Traduit du roumain par Claudia Drăgănoiu. 
En matière de représentation des horreurs communistes, on peut dire que Paul Goma est l'Alexandre Soljenitsyne des Roumains. Si L'Archipel $d u$ Goulag parait sept ans avant La passion selon Piteşti et rend son auteur presque instantanément célèbre, il faut pourtant souligner que, au-delà des différences évidentes, les deux œuvres se proposent de révéler la vérité sur le système carcéral communiste.

Dissident anticommuniste, personnalité controversée de l'exil roumain, Paul Goma montre dès sa jeunesse un esprit frondeur et contestataire le faisant exclure du lycée. Etudiant, il décide que la réforme intérieure peut être plus efficace que la contestation extérieure et adhère à l'Union des Jeunesses communistes. Il en est exclu en 1956, pour avoir ouvertement soutenu la révolution hongroise et se voit condamné à deux ans de prison correctionnelle (il en fera trois) à Jilava et à Gherla. Il est ensuite envoyé en résidence forcée dans le Baragan où il demeure jusqu'en 1964. Après avoir signé la «Charte $77 »^{2}$ en 1977 précisément, Goma est arrêté et torturé par la Securitate ${ }^{3}$ mais, comme il est connu à l'étranger, les communistes l'expulsent du pays avec sa femme et son fils et il se voit retirer la nationalité roumaine.

Après obtention de l'asile politique en France, Goma continue sa lutte contre le régime communiste roumain, ce qui entraîne pour lui des répercussions: la réception d'un colis piégé (désamorcé par la police française) et plusieurs tentatives d'empoisonnement contre lui-même et son fils (Manolescou, 2003: 357-363). Parallèlement ses livres témoignent à la fois de ses penchants nationalistes et d'une attitude assez hostile envers l'Occident, qu'il considère indifférent aux souffrances des peuples gouvernés par les communistes. C'est la raison pour laquelle il refuse la nationalité française, offerte au bout de trois ans de séjour, demeurant apatride jusqu'à aujourd'hui.

La passion selon Piteşti ou Les chiens de mort, livre sur lequel porte notre article, paru aux éditions Hachette en 1981 représente, dans une certaine mesure, le résultat de ses expériences carcérales. Bien que trop jeune pour avoir connu la rééducation de Pitești, Goma utilise, pour rendre son texte vraisemblable, les mémoires des survivants - Gheorghe Calciu et surtout

2 Une pétition des dissidents opposés au processus de «Normalisation» de la société tchécoslovaque (c'est-à-dire la période qui suit le Printemps de Prague et s'étend jusqu'à la Révolution de velours, 1968-1989) signifiant la reprise en main de l'appareil politique et économique par la ligne conservatrice du parti communiste tchécoslovaque.

3 Police politique secrète roumaine sous l'ère communiste. 
Dumitru Bacu. La plupart de ses personnages sont réels: Eugen Turcanu, Cornel Pop, Sura Bogdanovici, Petrica Fux - devenu dans son livre Fuhrmann (il était juif) - aussi que les événements décrits. D’ailleurs, leur véracité est confirmée par les témoignages des autres survivants de Piteşti.

Notre hypothèse de départ, c'est que ce roman représente une sorte de thérapie, dans sa tentative d'attribuer aux horreurs de Piteşti un sens suprême, d'y déchiffrer les signes d'une épreuve spirituelle assurant aux détenus qui l'ont traversée, l'accès à un niveau supérieur de connaissance, le plus souvent religieuse. En essayant de dépasser une expérience traumatisante, les survivants inclinent à reconfigurer la tragédie de Piteşti pour répondre aux exigences de la mystique orthodoxe de la conversion. Si le résultat de l'expérience a été, en effet, un homme «nouveau» comme le voulaient les communistes, cette transformation visait plutôt la révélation chrétienne que l'adhésion politique.

Écrivain talentueux ayant personnellement connu les prisons communistes, Goma a l'avantage d'une double perspective. D'un côté, son expérience le rend sensible aux témoignages de Piteşti, de l'autre, il est le Narrateur absolu, qui ne relate pas une histoire mais l'invente au fur et à mesure qu'il opère sa propre interprétation des événements. Cette position lui confère les droits d'un démiurge et elle influence aussi la perspective du personnage-narrateur Vasile Pop placé dès le début par Turcanu dans un "fauteuil d'orchestre», c'est-à-dire sur un lit à étage. Le détail est significatif car Vasile, témoin des tortures de la cellule 4 Hôpital, a aussi des qualités d'artiste musicien ou écrivain qu'il place au service de l'humanité en décidant de présenter au monde entier les crimes de Piteşti.

Une thérapie guérit le malade au moment où l'expérience traumatisante qui a causé le déséquilibre (d'ordre physique ou psychique) est assimilée et acceptée comme telle. Un tel processus ne peut commencer que par une présentation des faits historiques, dépourvus, dans une première étape, de toute subjectivité.

Entre 1949 et 1952, des expériences de lavage de cerveau et de rééducation par la torture ont eu lieu à Piteşti sous l'autorité du Parti Communiste Roumain. Ces traitements avaient pour but de forcer les détenus (des étudiants pour la plupart) à abandonner leurs convictions politiques et religieuses; on les torturait jusqu'au point où ils étaient prêts, à leur tour, à utiliser les mêmes méthodes pour "rééduquer» leurs camarades. Le groupe initial des détenus «rééducateurs» (car cette méthode a été mise en pratique, dès le début, par les détenus mêmes) était composé de prisonniers 
politiques dirigés par Eugen Turcanu, ancien étudiant à l'Université de Iasi, membre de la Garde de Fer devenu ultérieurement membre du PCR (Parti Communiste Roumain). Sous la supervision directe du commandant de Securitate Alexandre Nicolschi (de son vrai nom: Boris Grünberg) et de l'officier Iticovici Marina, Turcanu a choisi un groupe de détenus politiques déjà passés par la rééducation pour rééduquer, à leur tour, les autres détenus (le nom officiel du groupe était l'Organisation des détenus aux convictions communistes - ODCC).

Outre les supplices journaliers, les détenus étaient obligés de se torturer mutuellement, afin de décourager les anciennes amitiés. La rééducation débutait par des sessions d'endoctrinement politique, portant sur le matérialisme dialectique ou l'histoire du Parti communiste russe. Elle continuait avec les trois stages de la «dénonciation» - externe, interne et publique. Pour passer «l'examen» de la dénonciation externe, les détenus étaient forcés d'admettre sous torture les détails omis pendant les enquêtes antérieures. Le plus souvent, les prisonniers inventaient des "péchés» pour échapper à la torture. Si Turcanu ne trouvait pas les témoignages assez convaincants, il forçait les détenus à répéter jusqu'au moment ou il était persuadé de leur sincérité. La dénonciation interne visait à démasquer les «lrééducateurs» qui avaient trahi la cause en montrant de l'indulgence envers les autres prisonniers.

Enfin, l'humiliation publique constituait la dernière phase de la rééducation, quand les prisonniers devaient dénoncer l'ensemble des croyances, des idées et des valeurs personnelles. Une des méthodes préférées de Turcanu était l'organisation de mascarades blasphémant la Vierge, Jésus Christ ou les apôtres. Outre les valeurs chrétiennes, les détenus devraient aussi dénigrer les membres de leur famille, en décrivant, devant les autres prisonniers, des situations auxquelles ils auraient assisté - par exemple, leur père, le prêtre, violant les paroissiennes ou entretenant des relations incestueuses avec leurs enfants.

Une fois parvenu à ce dernier stade de la rééducation, Vasile Pop, l'alter ego de Goma, fait des déclarations grotesques ayant pour seul but de convaincre Turcanu de sa conversion. Au fur et à mesure que les tortures s'aggravent, les déclarations deviennent de plus en plus aberrantes, suggérant le désespoir de détenus qui perdent toute raison et dont le seul désir est d'échapper à la rééducation. Nous sommes en plein «1984» (roman de George Orwell): 
Concernant ma grand-mère paternelle, Pop Salomia, je déclare qu'elle est morte en octobre 1944, lorsque l'Armée Soviétique libératrice était en train de nous libérer. De la dictature fasciste. De la dictature d'Antonescu. Donc ma grand-mère est tombée du grenier est elle est morte.

Je, soussigné, Pop Vasile déclare que Pop Salomia est morte seule, de sa propre initiative, plus précisément de vieillesse. Et de maladie. Je déclare que ce n'est pas la faute des soldats soviétique libérateurs, je déclare que l'Armée rouge n'a rien à voir avec sa mort, qu'ils n'étaient pas montés au grenier pour la chercher, ni elle ni d'autres personnes et surtout pas des femmes.

Je, soussigné, Pop Vasile, déclare que l'Armée rouge libératrice n'est pas montée au grenier pour chercher des femmes. Par contre, elle nous délivrait des fascistes, donc Pop Salomia, s'est effrayée de sa propre initiative, et elle est tombée toute seule, sans être chassée ou brusquée, tout simplement parce qu'elle était très ivre et très vieille. (p. 213-214)

Voila les faits, voila les résultats visibles, c'est-à-dire ceux que les communistes pouvaient quantifier, numéroter, pour en extraire des statistiques justifiant leur réussite - encore un détenu rééduqué ou mort.

Ce n'est pourtant pas la chronologie historique qui suscite l'intérêt de Goma mais l'évolution spirituelle des détenus confrontés jour après jour à l'Enfer créé par Turcanu. Autrement dit «La passion selon Piteşti» est une ample ode à la folie généralisée issue de la terreur extrême et du désespoir affaiblissant le jugement bien que sauvant l'âme en la dérobant à la réalité.

La mémoire est seule à enregistrer les méandres de la psychose. Elle est "notre mère» avoue Vasile Pop au début du roman. Lui-même a été "remis» au monde par elle pour qu'il puisse revivre encore une fois sa fin, c'est-à-dire l'emprisonnement à Piteşti.

La narration à la première personne du singulier, suit l'expérience carcérale de Vasile Pop et de ses collègues de la cellule 4 Hôpital - nom réel de la cellule où Turcanu a commencé sa rééducation. Au début du roman, le personnage narrateur vient d'être transféré à Piteşti, après avoir connu d'autres prisons communistes. Les tortures prolongées, les trous creusés dans ses genoux avec le crayon chimique par un officier de la Securitate l'empêchent de se déplacer seul, et son handicap lui assure, au moins pour un temps, les faveurs de Turcanu, qui lui permet d'occuper un des lits des "rééduqués », bien qu'il n'ait pas encore subi la rééducation.

Vasile est le témoin constant des supplices, des peines et des humiliations subies par les autres détenus, pendant que lui-même souffre de ses genoux et a tout comme les autres, faim, froid et surtout peur. 
Le ton du récit reste détaché, comme si la douleur, les sentiments extrêmes éprouvés n'étaient pas siens, comme s'ils appartenaient à un autre, un prisonnier nommé aussi Vasile susceptible d'être observé à distance par l'auteur omniscient. Cette aliénation à soi est le signe le plus évident de l'égarement, du délire mais il y a encore d'autres détails, bien plus chiffrés.

Un des leitmotivs du roman est le souvenir obsédant du frère: Elisav, et de la petite sœur, la belle et innocente Seliva, violée et tuée par les soldats russes. L'explication de ces deux noms, aux résonances ésotériques, tient de la loi de la symétrie, laquelle répond aux exigences d'une personnalité accomplie. Le grand-père de Vasile croyait en effet que le nom d'une personne devait être choisi de manière à rester le même on le lisait de droite à gauche. Son nom de famille étant Pop, il avait nommé sa fille Ana et avait obligé son gendre à changer son prénom en Tit. Lorsque ses petits-fils jumeaux sont nés, il a réglé le problème en les nommant Vasile (nom du personnage-narrateur du roman) et Elisav, pour conserver la symétrie. De surcroît, il a nommé sa petite-fille Seliva - acronyme du même nom.

Si Vasile n'a aucun doute sur le sort de Seliva, Elisav demeure, à travers le roman, une présence mystérieuse dont le rôle est d'encourager Vasile dans ses plus sombres moments. Le détenu ne survit que pour voir Elisav, qu'il croit enfui à l'étranger devenir chef des partisans, luttant contre les communistes et venir le sauver. À tout moment, Elisav est son double, son alter ego, sa projection dans le monde libre, outre les murs de la prison.

La grille de lecture que j'envisage parce qu'elle me paraît plus cohérente dans le contexte d'une aliénation progressive menant à la démence, est qu'en fait Elisav et Seliva sont deux personnalités alternatives du même individu - Vasile - apparues dans des conditions extrêmes.

La psychose se manifesterait aussi dans le domaine du langage des protagonistes: celui-ci a deux niveaux quelquefois interchangeables.

Le premier, celui du personnage-narrateur Vasile et des détenus en général, est cultivé. Sa syntaxe est complexe, il témoigne de l'humour, de l'ironie de ses utilisateurs. Nulle subtilité ici - la plupart des prisonniers de Piteşti sont des étudiants que leur éducation antérieure (celle que les communistes tentent d'anéantir) a rendu ouverts aux questions de l'esprit. Ne nous laissons pas tromper, pourtant! L'aliénation est toujours présente dans la manière de s'exprimer. La proposition se voit souvent coupée au milieu, refusant d'admettre des mots terribles - bien que leur suppression puisse aussi terrifier. "Crie plus fort, Vasile, sinon il va faire venir Balan 
pour...»; «Frappe plus fort, Mihai, sinon il va faire venir Balan pour...»; «Toi aussi, Mihai, frappe plus fort pour qu'il ne...» (p. 198).

Il s'agit, en fait d'une sorte d'expérience - est-ce que, soutenu par le contexte général, le sens peut subsister sans les mots qui le soutiennent?

Le deuxième niveau du langage est plus susceptible encore d'être considéré comme une innovation. Il s'agit du langage des gardiens, des tortionnaires et surtout de Turcanu. La plupart du temps ce langage se situe à la limite d'un dialecte étrange qui n'a été encore inventé. Goma ne présente pas ici un argot réel, connu pendant son emprisonnement, mais un langage qui, selon son imagination, aurait été utilisé par les bourreaux de Pitești. Grossier, souvent incorrect, offensant, il s'appuie sur un fond lexical extrêmement bariolé. Vasile Pop remarque: les officiers de la Securitate ne connaissent pas plus de cent mots, dont quatre-vingt sont des injures.

La dimension religieuse, comme je le mentionnais plus haut, est une autre dimension fondamentale du roman. Le motif de la conversion au communisme, autour duquel tourne le phénomène de la rééducation s'entremêle à celui de la conversion religieuse - d'ailleurs, l'allusion du titre du roman («Passion selon Piteşti») est suffisamment transparente.

La mise, pour les détenus, c'est d'identifier correctement, sous une pression extrême, les attributs véritables de la divinité. S'agit-il d'un pouvoir immédiat, écrasant, punitif (voir Turcanu, souvent comparé au Dieu) ou d'une promesse vague de vie éternelle (voir Vasile Pop, qui oppose à la cruauté toute puissante de Turcanu l'idée d'éternité, obtenue grâce à la mémoire)?

L'idée qui s'impose est que les détenus de Piteşti, rééduqués ou non, figurent les innombrables facettes du Christ, mort sur la croix, et dont les péchés des hommes ne font que réaffirmer l'humanité.

Finalement, la dernière partie du livre s'occupe de procès de Turcanu et de quelques rééduqués que les communistes ont condamnés à mort. La question qui nous hante, aujourd'hui même, lorsqu'il s'agit de ce sujet est «A-t-il existé aussi des bourreaux à Piteşti, ou seulement des victimes?». 


\section{Bibliographie}

Goma P., 20044, Patimile după Piteşti, http://foaienationala.files.wordpress.com/2009/08/ paul-goma-patimile-dupa-Piteşti.pdf

Bacu D., 1989, Piteşti. Centru de reeducare studențească, Ed. Cuvântul Românesc, Hamilton.

Cesereanu R., 2006 (coord.), Comunism şi represiune în România. Istoria tematică a unui fratricid național, Ed. Polirom, Iassy.

Ierunca V., 2007, Fenomenul Piteşti, préface de François Furet, troisième édition, Ed. Humanitas, Bucarest.

Manolescu, F., 2003, Enciclopedia exilului literar romanesc 1945-1989: scriitori, reviste, institutii, organizatii, Ed. Compania, Bucarest, p 357-363. 